\title{
Frequency Dependence of Fatigue Life and Internal Heating of a Fiber-Reinforced/Ceramic-Matrix Composite
}

\author{
John W. Holmes, ${ }^{*}$ Xin Wu, ${ }^{*}$ and Bent F. Sørensen* \\ Ceramic Composites Research Laboratory, Department of Mechanical Engineering and Applied Mechanics, \\ The University of Michigan, Ann Arbor, Michigan 48109-2125
}

\begin{abstract}
The influence of loading frequency on the fatigue life and internal (frictional) heating of unidirectional SiC-fiber/ calcium aluminosilicate-matrix composites was investigated at room temperature. Specimens were subjected to tensiontension fatigue at sinusoidal loading frequencies from 25 to $350 \mathrm{~Hz}$ and maximum fatigue stresses of 180 to $240 \mathrm{MPa}$. The key findings of the study were that (1) fatigue life decreased sharply as the loading frequency was increased, (2) for all loading frequencies, fatigue failures occurred at stress levels that were significantly below the monotonic proportional limit stress of $\sim 285 \mathrm{MPa}$, and (3) pronounced internal heating occurred during fatigue, with the surface temperature of the fatigue specimens increasing by $160 \mathrm{~K}$ during $350-\mathrm{Hz}$ fatigue at a peak stress of $240 \mathrm{MPa}$.
\end{abstract}

\section{Introduction}

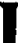
NVESTIGATIONS of the stress dependence of fatigue life and fatigue damage accumulation in fiber-reinforced ceramics have typically been conducted at loading frequencies of $10 \mathrm{~Hz}$ or lower. ${ }^{1-11}$ To date, the influence of loading frequency on the fatigue life of fiber-reinforced ceramics has not been investigated. Loading frequency has been shown to have little effect on the room-temperature fatigue life of monolithic ceramics, even at loading frequencies as high as several thousand hertz. ${ }^{12}$ However, since interfacial sliding and wear occur during the fatigue of fiber-reinforced ceramics, it is possible that loading frequency, which influences the rate and degree of interfacial wear, can result in a frequency dependence of fatigue life. In addition, recent studies have shown that substantial frequencydependent internal (frictional) heating occurs during the fatigue of fiber-reinforced ceramics. ${ }^{13-15}$

The purpose of the present communication is to report on recent experimental findings that provide clear evidence for a frequency dependence of fatigue life in Nicalon/calcium aluminosilicate composites that have been subjected to tension-tension fatigue at frequencies between 25 and $350 \mathrm{~Hz}$. The paper also discusses the frequency dependence of internal heating.

\section{Experimental Procedure}

Unidirectional 16-ply Nicalon (SiC)/calcium aluminosilicate composites ([0] $\left.{ }_{16}-\mathrm{Nicalon} \mathrm{SiC}_{\mathrm{f}} / \mathrm{CAS}-\mathrm{II}\right)$ were used in the investigation (processed by Corning Glass Works, Coming, NY). Edge-loaded tensile specimens were removed from the billets such that the fibers were aligned parallel to the intended tensile loading direction (further details of the specimen geometry can

G. Grathwohl-contributing edilor

\footnotetext{
Manuscript No. 193874, Received January 29, 1994; approved May 16, 1994

${ }^{*}$ Member, American Ceramic Society.

Presented in part at the 17th Annual Conference on Composites and Advanced Ceramics, Cocoa Beach, FL, January 10-15, 1993 (Paper No. C-145-93F).
}

*Visiting scientist from Risø National Laboratory, 4000 Roskilde, Denmark be found in Ref. 14). The broad faces of the specimens were not machined to avoid damage of near-surface fibers.

The fatigue experiments were conducted on a servohydraulic load-frame (Model 331, MTS Systems Corp., Minneapolis, $\mathrm{MN}$, resonant frequency of $\sim 500 \mathrm{~Hz}$ ). Infrared pyrometers were used to measure the temperature increase of the specimen surface during the fatigue experiments. The pyrometers, focused at the center of the gage section, had a spot size of 5 $\mathrm{mm}$ at the specimen surface. Temperature data were gathered at a frequency of $20 \mathrm{~Hz}$. The specimen, grips, pyrometers, and piezoelectric load cell were surrounded by an isothermal test chamber that had an enclosed volume of $0.1 \mathrm{~m}^{3}$. The temperature within the chamber and at the specimen ends was maintained at $20^{\circ} \pm 0.1^{\circ} \mathrm{C}$ by a closed-loop water chiller that circulated coolant through the chamber walls and grips. Further details concerning the experimental approach can be found in Ref. 13.

Specimens were subjected to continuous fatigue loading at sinusoidal frequencies of $25,75,150$, and $350 \mathrm{~Hz}$. All experiments were conducted under load control (i.e., the maximum and minimum load limits were fixed). Maximum fatigue stresses of $180,200,220$, and $240 \mathrm{MPa}$ were examined; in all cases the minimum cyclic stress was $10 \mathrm{MPa}$. The stress ratio $\left(\sigma_{\min } / \sigma_{\max }\right)$ ranged from approximately 0.055 at $180 \mathrm{MPa}$ to 0.042 at $240 \mathrm{MPa}$. Fatigue run-out was defined at $5 \times 10^{6}$ cycles, corresponding to approximately $55.5 \mathrm{~h}$ of testing at 25 $\mathrm{Hz}$ and $4 \mathrm{~h}$ at $350 \mathrm{~Hz}$. These experiments provided information on the stress and frequency dependence of frictional heating and conventional stress versus cycles to failure data (i.e., an "SN" curve).

\section{Results and Discussion}

\section{(1) Monotonic Tensile Behavior}

The room-temperature monotonic tensile behavior of the composite is shown in Fig. 1. The composite exhibited a linear stress-strain response to a stress of approximately $285 \mathrm{MPa}$ (defined as the proportional limit stress), followed by progressive nonlinear behavior until $350 \mathrm{MPa}$, whereafter the stressstrain curve was again linear to the failure stress (roughly 590 $\mathrm{MPa}$ ). Previous studies had shown that matrix microcracking in Nicalon/CAS-II composites could occur at stress levels as low as $50 \%$ of the monotonic proportional limit stress. ${ }^{14-16}$ Thus, the fatigue stress levels used in this study, which ranged from $63 \%$ to $84 \%$ of the proportional limit stress, were sufficiently high to ensure that microstructural damage and internal heating would occur during fatigue loading.

\section{(2) Influence of Loading Frequency on Fatigue Life}

The fatigue life (cycles to failure) of the composite is shown in Fig. 2 as a function of maximum fatigue stress and loading frequency. At a maximum fatigue stress of $180 \mathrm{MPa}$, fatigue run-out was observed for all loading frequencies. For stresses above $180 \mathrm{MPa}$, the fatigue life decreased markedly as the loading frequency was increased. For example, for a loading frequency of $25 \mathrm{~Hz}$ and a fatigue stress of $220 \mathrm{MPa}$, no fatigue 


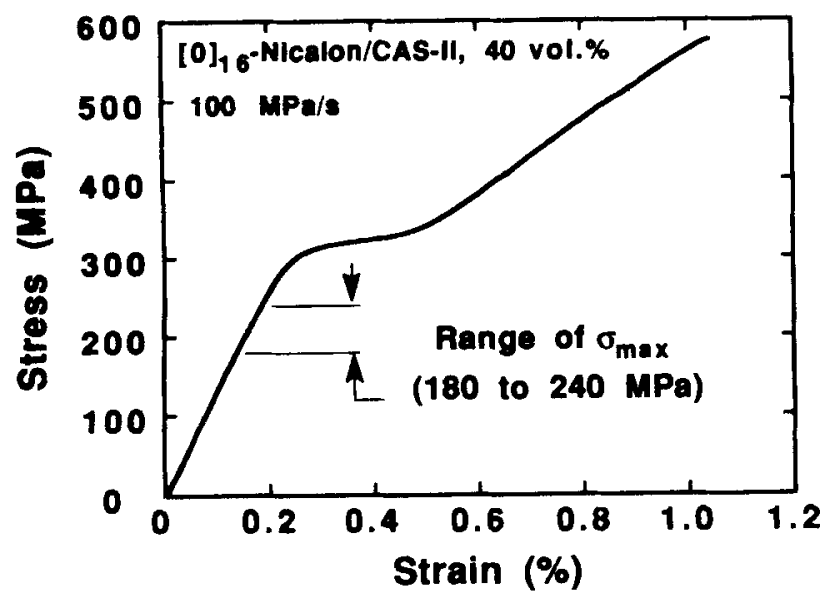

Fig. 1. Room-temperature monotonic tensile behavior of $40 \mathrm{vol} \%$ $[0]_{16}$-Nicalon/CAS-II. Tensile testing was conducted at rate of 100 $\mathrm{MPa} / \mathrm{s}$ to minimize influence of time-dependent matrix cracking on measured modulus and stress strain behavior. Initial tangent modulus was approximately $130 \mathrm{GPa}$, and proportional limit stress ranged from 280 to $295 \mathrm{MPa}$ (based upon measurements from three experiments).

failures occurred within $5 \times 10^{6}$ cycles, whereas, for $350 \mathrm{~Hz}$, fatigue failure occurred as early as 42000 cycles. Although fatigue failures were not observed within $5 \times 10^{6}$ cycles during $25-\mathrm{Hz}$ cycling at a maximum stress of $220 \mathrm{MPa}$, it should not be concluded that a true fatigue limit existed for any of the loading frequencies examined. Longer-duration experiments are required to ascertain if a true fatigue limit exists for Nicalon/ CAS-II and other fiber-reinforced ceramics.

It is important to note that all of the fatigue experiments have been conducted at maximum stresses ( 180 to $240 \mathrm{MPa}$ ) below the average monotonic proportional limit stress of $285 \mathrm{MPa}$ measured with virgin specimens. It sometimes has been found that the proportional limit stress provides a rough approximation for the fatigue limit of many unidirectional fiber-reinforced ceramics. $^{2,4,11}$ However, the results obtained from the present study clearly show that the proportional limit stress cannot be used to predict the room-temperature fatigue limit of fiberreinforced ceramics subjected to high loading frequencies. Also, the occurrence of frictional heating at stresses as low as $180 \mathrm{MPa}$ indicates that microstructural damage begins at

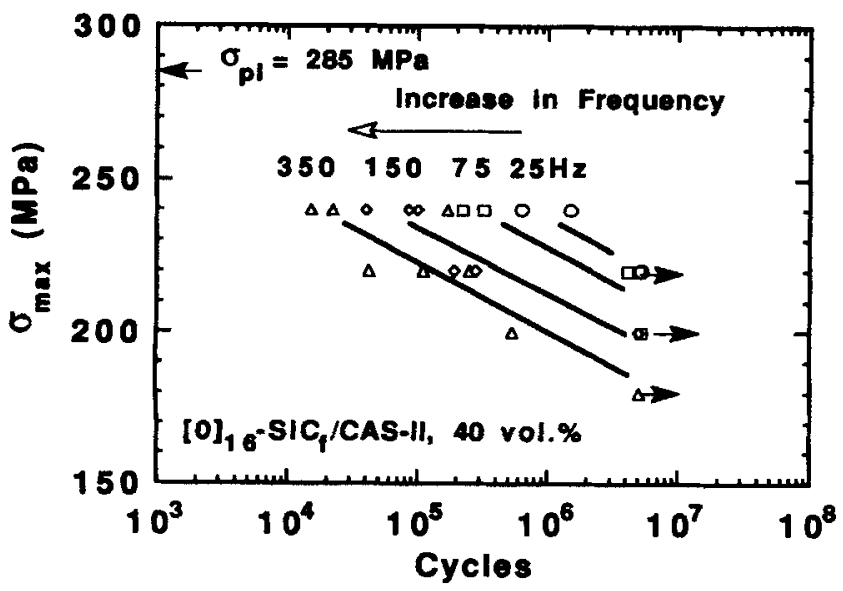

Fig. 2. Influence of maximum fatigue stress and sinusoidal loading frequency on room-temperature fatigue life of $[0]_{16}$-Nicalon/CAS-II composites. The minimum fatigue stress was $10 \mathrm{MPa}$ for all loading frequencies. Although there was considerable scatter in data, fatigue life clearly decreased with increased loading frequency (lines shown for each loading frequency represent power-law fit to raw data). Fatigue run-out (defined at $5 \times 10^{6}$ cycles) was observed at $180 \mathrm{MPa}$ for all loading frequencies. fatigue stresses that are substantially below the monotonic proportional limit stress.

\section{(3) Frictional Heating during Fatigue}

As discussed in detail elsewhere, ${ }^{10,14,15}$ the repeated frictional slip of fibers along debonded interfacial slip zones can lead to significant internal heating during the fatigue of fiberreinforced ceramics. The frequency dependence of surface temperature increase is plotted in Fig. 3(A) for specimens that were fatigued at a maximum stress of $220 \mathrm{MPa}$. As shown in Fig. 3(A), the temperature increase is strongly influenced by loading frequency. Because a finite number of cycles are required to propagate matrix cracking and associated interfacial debonding, and due to the finite time required for heat conduction to the specimen surface, there is an initial lag before a temperature increase is detected. For specimens fatigued at 25 or 75 $\mathrm{Hz}$, the temperature increases slowly, reaches a plateau, and then slowly decreases. For specimens fatigued at 150 or 350 $\mathrm{Hz}$, the temperature increases continually to the point of specimen failure, indicating a progressive increase in microstructural damage accumulation.

In addition to loading frequency, the temperature increase of the specimen and shape of the temperature curves are also influenced by maximum fatigue stress. For example, as shown in Fig. 3(B) for a loading frequency of $350 \mathrm{~Hz}$, the maximum temperature increase changed from approximately $40 \mathrm{~K}$ at a
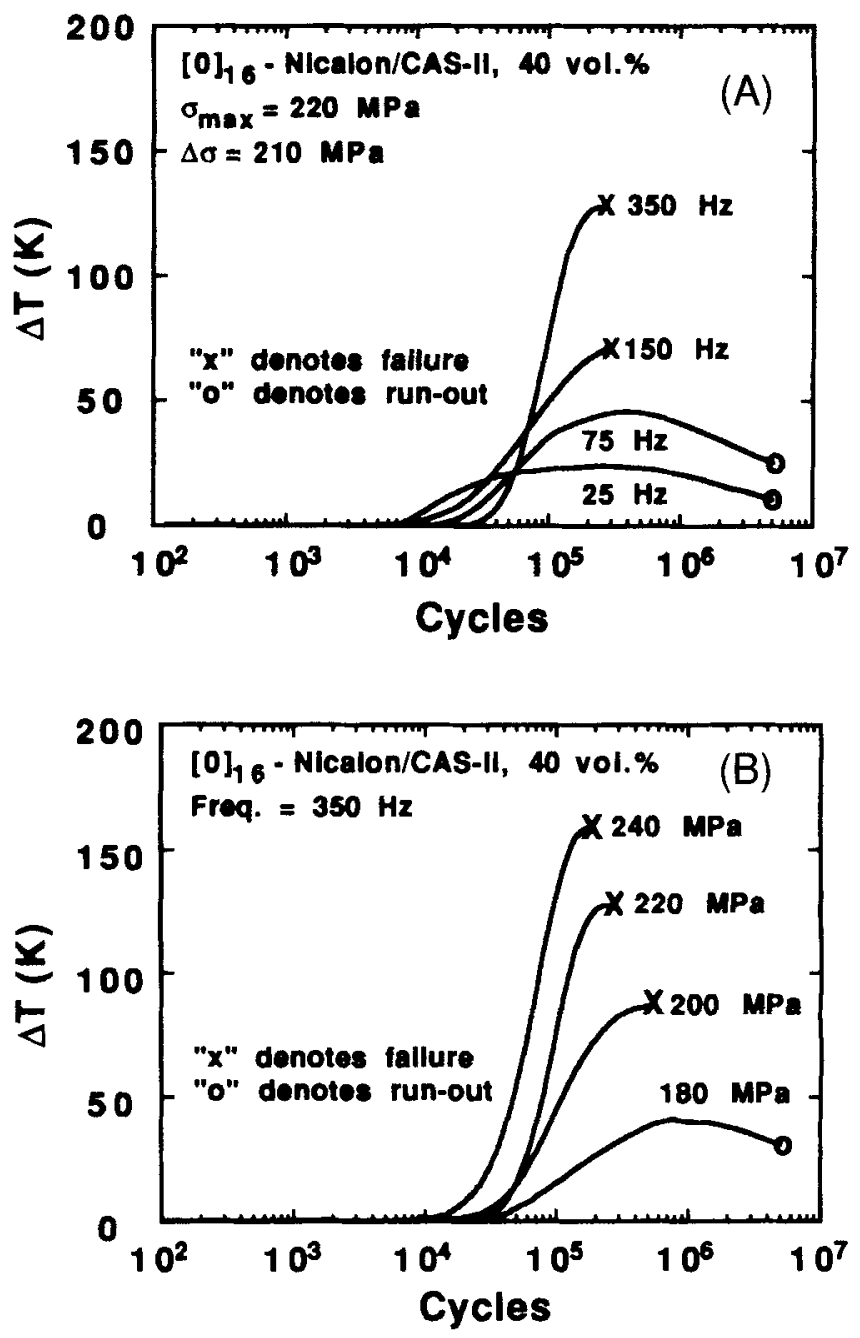

Fig. 3. (A) Influence of loading frequency on temperature increase $\left(T-T_{\text {ambient }}\right)$ of $[0]_{16}$-Nicalon/CAS-II composites fatigued between stress limits of 220 and $10 \mathrm{MPa}$. (B) Influence of maximum fatigue stress on temperature increase $\left(T-T_{\text {ambicnt }}\right)$ of $\left[\left.0\right|_{16}\right.$-Nicalon/CAS-II composites fatigued at a sinusoidal loading frequency of $350 \mathrm{~Hz}$. Lower fatigue stress was $10 \mathrm{MPa}$ for all cases. 
peak fatigue stress of $180 \mathrm{MPa}(\Delta \sigma=170 \mathrm{MPa})$ to $160 \mathrm{~K}$ at $240 \mathrm{MPa}(\Delta \sigma=230 \mathrm{MPa})$.

\section{(4) Comments Regarding Frequency Dependence of Fatigue Life and Temperature Increase}

The precise mechanisms that result in frequency dependence of fatigue life and microstructural damage accumulation are not known at this time. However, it is of interest to speculate on possibie mechanisms of fatigue damage based upon the insight gained from this study and from other studies ${ }^{1-15}$ of fatigue effects in ceramic-matrix composites. If the governing failure mechanism during fatigue loading is time-dependent subcritical crack growth under a mean stress, the failure time at a given stress level would be independent of loading frequency. The experimental results show that the failure time decreases as loading frequency increases. Although time-dependent phenomena can affect the mechanical fatigue of ceramics, it has been clearly shown by others that mechanical crack growth can occur during the fatigue loading of monolithic ceramics and ceramic-matrix composites.

There are mechanisms that can cause an enhanced temperature increase and a fatigue life decrease with increasing loading frequency. We review some of the mechanisms that can lead to failure, and, afterward, we discuss how the effect of frequency can influence the fatigue life. In the initial stages of fatigue, the fiber/matrix interface can be worn down during repeated forward and backward sliding between fiber and matrix. ${ }^{17}$ This lowers the interfacial normal pressure and (assuming Coulomb friction) the interfacial sliding shear stress. The load-transfer length increases as wear progresses. According to models by Curtin $^{18}$ and Rowby and Reynaud, ${ }^{19}$ this leads to a reduction in composite strength. A lower interfacial shear stress also leads to a temperature increase if only partial sliding occurs along the interface (the sliding length is shorter than half the crack spacing); however, once the interfacial shear stress has decreased so much that sliding exists along the entire interface, the temperature increase is decelerated with decreasing values of the interfacial shear stress. ${ }^{14} \mathrm{Next}$, repeated forward and backward sliding at the interface may induce abrasive wear damage to the surface of the fibers, creating new sites that can promote fiber failure. This leads to progressive damage of the fibers (fatigue). Furthermore, when the number of broken fibers increases, the temperature increase accelerates since a broken fiber slides over a longer distance than an intact fiber.

What, however, is the effect of loading frequency? Obviously, a higher frequency causes a higher temperature, and this may accelerate damage accumulation, as follows. With increasing temperature, the residual stresses decrease, lowering the interfacial pressure and shear stress. This, according to the composite strength models, ${ }^{18,19}$ leads to a decrease in strength. Abrasive wear-induced damage at the fibers is also likely to be temperature and velocity dependent. The local temperature increase along the fiber/matrix interface, which is higher than the bulk temperature, can potentially influence chemical diffusion rates near the interface or cause oxidation of the carbon interfacial layers.

Current research is focused on microscopy at the SEM and TEM levels to document the evolution of microstructural damage; these results, and the results of mechanics modeling of high-frequency fatigue damage will be reported in a future paper.

\section{Conclusions}

An initial study of the frequency dependence of fatigue life in fiber-reinforced/ceramic-matrix composites was conducted. It was found that the tension-tension fatigue life of Nicalon/CAS composites was strongly influenced by loading frequency, which decreased as the loading frequency was increased. For example, at a peak stress of $220 \mathrm{MPa}$, the fatigue life decreased from $5 \times 10^{6}$ cycles (run-out) at frequencies of 25 and $75 \mathrm{~Hz}$, to less than 50000 cycles at $350 \mathrm{~Hz}$. Fatigue failures were observed at maximum stresses that were significantly less than the monotonic proportional limit stress. Additional work in progress is directed at identifying how loading frequency influences microstructural damage accumulation.

\section{References}

${ }^{'}$ E. Minford and K. M. Prewo, "Fatigue of Silicon Carbide-Reinforced Lithium Aluminosilicate Glass-Ceramics"; pp. 561-70 in Tailoring Multiphase and Composite Ceramics. Edited by C. G. Patano and G. L. Messing. Plenum, New York, 1986.

${ }^{2}$ K. M. Prewo, "Fatigue and Stress Rupture of Silicon Carbide-Fibre-Reinforced Glass-Ceramics," I. Mater. Sci., 22, 2695-701 (1987).

${ }^{3} \mathrm{C}$ Q Rousseou, "Monotonic and Cyclic Behavior of Silicon Carbide/ Calcium Aluminosilicate Ceramic Composites"; pp. 136-51 in Thermal and Mechanical Behavior of Metal-Matrix and Ceramic-Mairix Composites, ASTM STP 1080. Edited by J. M. Kennedy, H. H. Moeller, and W. S. Johnson. American Society for Testing and Materials, Philadelphia, PA, 1990.

${ }^{4}$ L. P. Zawada, L. M. Butkus, and G. A. Hartman, "Room-Temperature Tensile and Fatigue Properties of Silicon Carbide-Fiber-Reinforced Aluminosilicate Glass," Ceram. Eng. Sci, Proc, 11 [9-10] 1592-606 (1990).

${ }^{5} \mathrm{P}$. G. Karandikar and T.-W. Chou, "Microcracking and Elastic Moduli Reductions in Unidirectional Nicalon-CAS Composites under Cyclic Loading," Ceram. Eng. Sci. Proc, 13 [9-10] 881-88 (1992).

${ }^{6}$ P. G. Karandikar and T.-W. Chou, "Damage Development and Moduli Reductions in Nicalon-CAS Composites under Static Fatigue and Cyclic Fatigue," J. Am. Ceram. Soc., 76, 1720-28 (1993).

${ }^{7}$ E. Y. Luh, R. H. Dauskardt, and R. O. Ritchie, "Cyclic Fatigue-Crack Growth Behavior of Short Cracks in SiC-Reinforced LAS Glass-Ceramic Composites," J. Mater. Sci. Lett., 9, 719-25 (1990).

"R. F. Allen and P. Bowen, "Fatigue and Fracture of a SiC/CAS ContinuousFiber-Reinforced Glass-Ceramic-Matrix Composite at Ambient and Elevated Temperatures," Ceram. Eng. Sci. Proc., 14, 265-72 (1993).

"R. F. Allen and P. Bowen, "Effects of Test Temperature and Loading Rate on the Fatigue and Fracture Resistance of a Continuous-Fibre-Reinforced GlassCeramic-Matrix Composite"; in Proceedings of the Ninth International Conference on Composite Materials (ICCM-9), July 12-16, 1993, Madrid, Spain, in press.

${ }^{10} \mathrm{~J}$. W. Holmes, "Fatigue of Fiber-Reinforced Ceramic Composites"; pp. 193 238 in Ceramics and Ceramic Matrix Composites, Vol. 3, Flight-Vehicle Materials. Structures, and Dynamics-Assessment and Future Directions. Edited by S. R. Levine, ASME, New York, 1992.

"J. W. Holmes, T. Kotil, and W. T. Foulds, "High-Temperature Fatigue of SiC-Fibre-Reinforced $\mathrm{Si}_{3} \mathrm{~N}_{4}$ Ceramic Composites"; pp. 176-86 in Proceedings of Symposium on High-Temperature Composites. Technomics, Basel, Switzerland, and Lancaster, U.K., 1989.

${ }^{12}$ M. Masuda, N. Yamada, T. Soma, M. Matusi, and I. Oda, "Cyclic Fatigue Properties of Sintered $\mathrm{Si}_{3} \mathrm{~N}_{4}$ at Room Temperature,"J. Ceram. Soc. Jpn. Int. Ed., 97, 509-14 (1989).

${ }^{13}$ J. W. Holmes and S. F. Shuler, "Temperature Rise during Fatigue of FibreReinforced Ceramics," J. Mater. Sci. Lett., 9, 1290-91 (1990).

${ }^{14} \mathrm{~J}$. W. Holmes and C. Cho, "Frictional Heating in a Unidirectional FiberReinforced Ceramic Composite," J. Mater. Sci. Lett., 11, $41-44$ (1992).

${ }^{5}$ J. W. Holmes and C. Cho, "Experimental Observations of Frictional Heating in Fiber-Reinforced Ceramics," J. Am. Ceram. Soc., 75 [4] 929-38 (1992).

B. F. Sørensen and R. Talreja, "Analysis of Damage in a Ceramic-Matrix Composite,"Int. J. Damage Mech., 2, 246-71 (1993).

${ }^{17}$ T. J. Mackin, P. D. Warren, and A. G. Evans, "Effects of Fiber Roughness on Interfacial Sliding in Composites," Acta Metall. Mater., 40, 1251-57 (1992).

${ }^{18}$ W. A. Curtin, "Theory of Mechanical Properties of Ceramic-Matrix Composites,"J. Am. Ceram. Soc., 74, 2837-45 (1991).

${ }^{19}$ D. Rouby and P. Reynaud, "Fatigue Behaviour Related to Interface Modification during Load Cycling in Ceramic-Matrix Composites," Compos. Sci. Technol., 48, 109-18(1993). 